\title{
China's ongoing battle against the coronavirus: Why did the lockdown strategy work well?
}

\author{
Liding Chen ${ }^{1} \cdot$ Xingzhong Yuan ${ }^{2}$
}

Received: 10 March 2020 / Accepted: 29 March 2020

(c) Springer Nature Singapore Pte Ltd. 2020

\begin{abstract}
"Why did the lockdown strategy work well in China's ongoing battle against the coronavirus pandemic?"is one of the three questions the journal editor Wei-Ning Xiang asked us to respond to from our experiences in the past several months since December 2019. At this critical juncture when the people in China are progressing on the battleground, we dedicate this communication essay to all the people fighting against the pandemic around the world.
\end{abstract}

Keywords The coronavirus pandemic $\cdot$ COVID-19 China $\cdot$ The lockdown strategy $\cdot$ Socio-ecological network $\cdot$ Human health $\cdot$ Ecosystem health $\cdot$ Chinese calligraphy $\cdot$ Meditation $\cdot$ Roof garden $\cdot$ Work-at-home

\section{Why did the lockdown strategy work well?}

In China's ongoing battle against the coronavirus pandemic, an effective strategy is to lock down cities, towns, villages, neighborhoods, and homes. As ecologists, Professors Chen and Yuan, how would you explain why such a strictly implemented strategy worked so well?

A question from SEPR editor Wei-Ning Xiang ${ }^{1}$

\subsection{The essence of the lockdown strategy}

As ecologists, we view cities, towns, villages, neighborhoods, and homes as connected nodes on a socio-ecological network. A socio-ecological network consists of intertwined human-centric networks (e.g., a railway network, a public transit system, an air route network) and natural networks (e.g., a river, a conservation corridor, a bird migration route). While operating to primarily serve human needs,

Liding Chen

liding@rcees.ac.cn

Xingzhong Yuan

1072000659@qq.com

1 Research Center for Eco-Environmental Sciences, Chinese Academy of Sciences, Beijing 100085, China

2 Faculty of Architecture and Urban Planning, Chongqing University, Chongqing 400030, China these component networks also benefit (or obstruct) other beings, including germs that are detrimental to human health. The coronavirus is only a most recent "beneficiary" of this kind. As such, the essence of the lockdown strategy is to lock down all the nodes on a socio-ecological network, preventing this deadly virus from transmitting from node to node. When strictly implemented, the strategy should work theoretically; in practice, it did work well in China this time.

Below are further elaborations.

\subsection{From ecological network to socio-ecological network}

An ecological network is traditionally defined as a natural or human-built system of connected habitats for biological conservation in cities, towns, and countryside. The links and nodes (i.e., corridors and habitats) of an ecological network operate coherently to provide the target species a fitting environment for survival, reproduction, and flourishing. As cities, towns, and even countryside become more urbanized, ecological networks in the traditional sense are increasingly intertwined with human-centric networksbiological, cultural, digital, economic, political, social, and technological - that operate to serve human needs. Together, they form an emergent socio-ecological network whose component networks interact with each other to serve primarily

\footnotetext{
${ }^{1}$ We received invitations to respond to this and other questions (see the following sections of this essay) from Wei-Ning Xiang (wxiang@ uncc.edu) on March 6, 2020.
} 


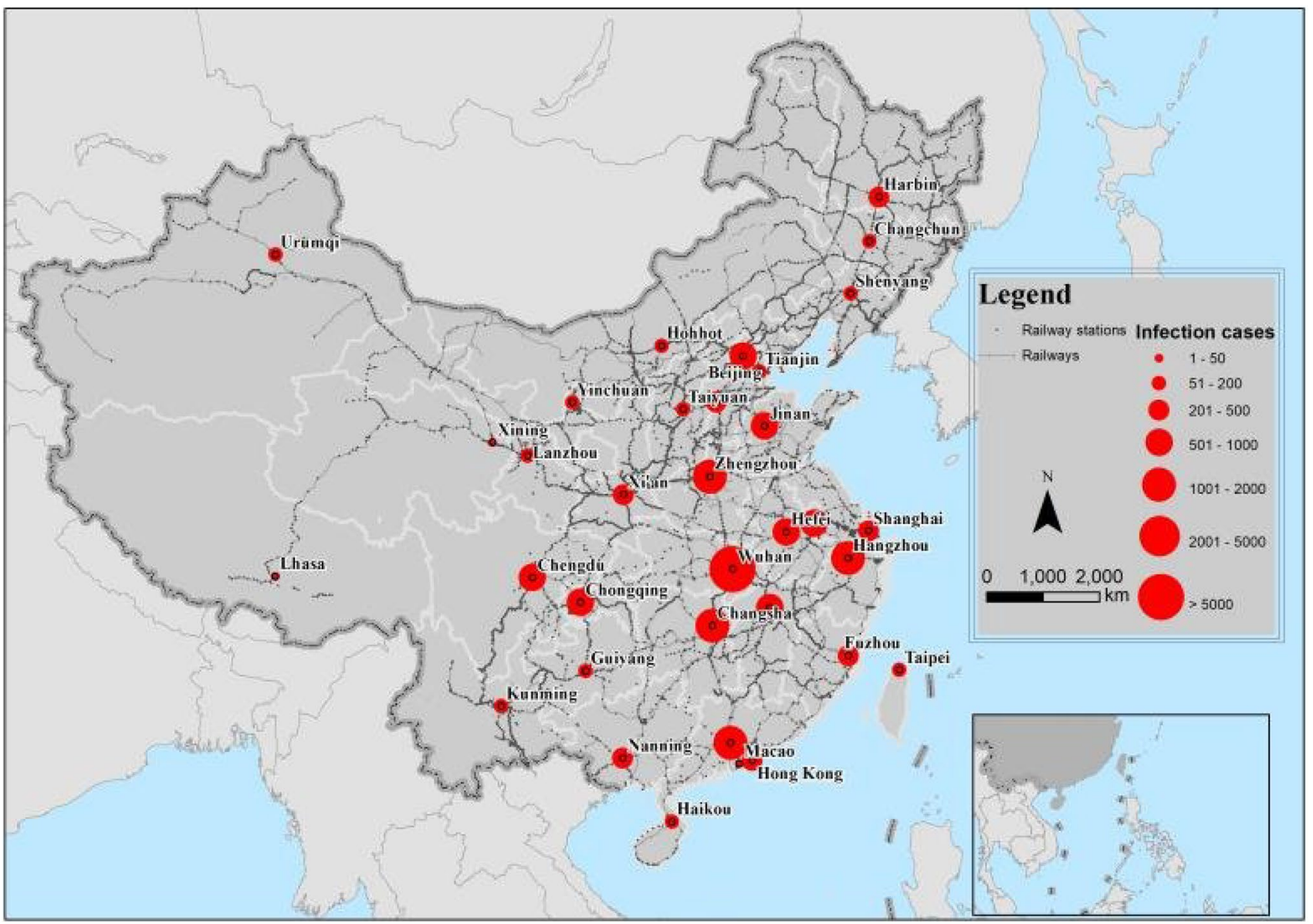

Fig. 1 The coronavirus infection hot spots in China as of March 22, 2020 , in relation to the countrywide railway system (the countrywide railway system is a component of the emergent socio-ecological network. It serves the needs of the human beings, but also nonexclusively "benefits" other beings, including germs that are detrimental to human health. Wuhan is a major hub on the countrywide socioecological network owing to its central location in China. As shown in the figure, it had the highest number of infection cases). Note Data used in the mapping are downloaded on March 22, 2020, from the following sources: https://dataverse.harvard.edu/dataset.xhtml?persi stentId=doi:10.7910/DVN/JIISNB (high-speed railway system); https://download.geofabrik.de/asia/china.html(traditional railway system); andhttp://fms.news.cn/swf/2020_sjxw/2_1_xgyq/index $. h t m l ? v=0.26920261822014924$ (the infection cases)
Fig. 2 Neighborhoods on lockdown (left: The neighborhood author Liding Chen lives in Beijing has been on lockdown since January 23, 2020. Right: At the neighborhood entrance, reentering residents are required to take temperature test. Photographs provided by Liding Chen)

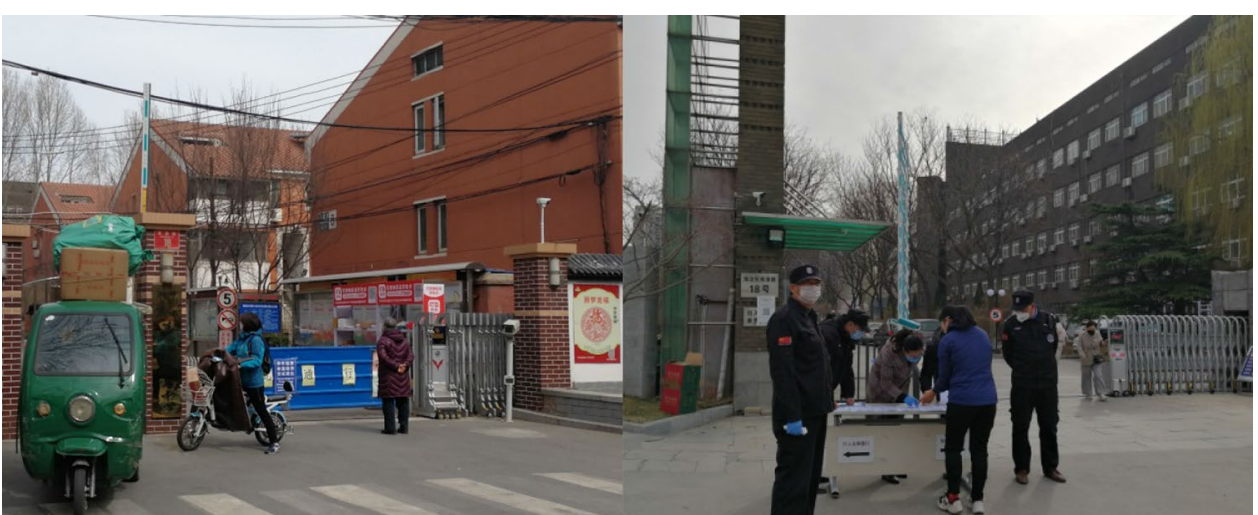


Fig. 3 Liding Chen's hobbies during voluntary home self-isolation (left: the corner at author Liding Chen's home in Beijing where he practices Chinese calligraphy daily. Right: the foot massage machine he uses in the evening before going to bed. Photographs provided by Liding Chen)
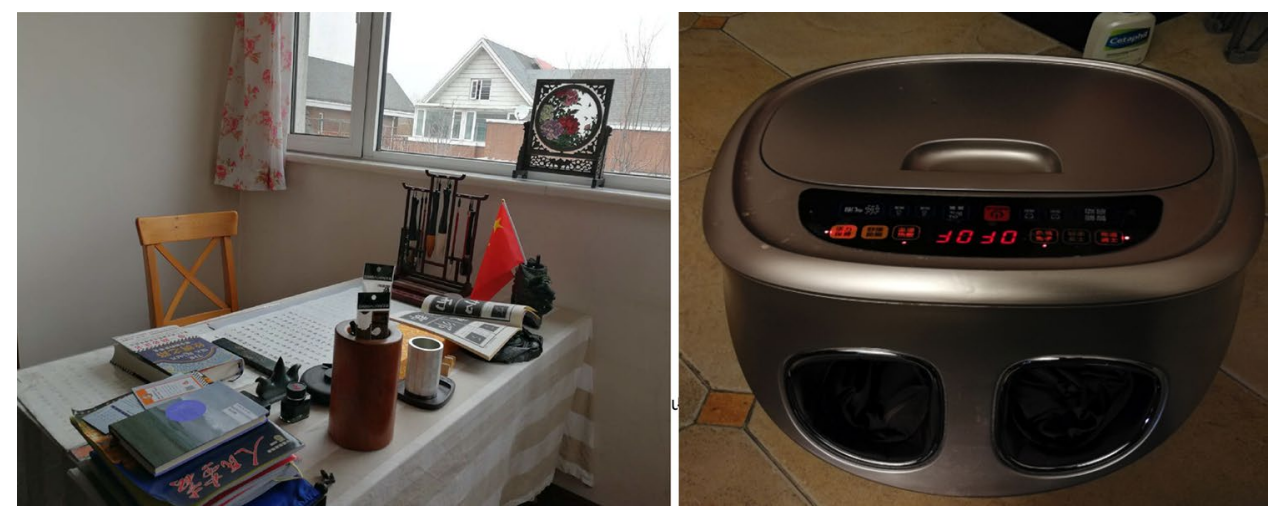

human needs as well as the needs of other beings (e.g., the target species).

\subsection{A socio-ecological network provides non-excludable benefits}

Unfortunately, these "other beings" that benefit from a socioecological network also include those germs that are pernicious to human health. The coronavirus is but a most recent "target species" of this kind. In the past several months since December 2019, it first violently attacked Wuhan, the populous unban center in central China; through an extensive citywide socio-ecological network, it readily ignited a devastating outbreak among the 11 million unprepared people throughout the Three Towns of Wuhan; later via a widespread countrywide socio-ecological network on which Wuhan is a hub, it extended the pernicious assault comfortably to other parts of the country, causing a deadly pandemic among the 1.4 billion people (Fig. 1). ${ }^{2}$

\subsection{A node lockdown strategy at work}

From this daunting reality, practitioners in China learnt the hard way about the critical role socio-ecological networks played in the coronavirus pandemic. They wasted no time and expeditiously took a series of effective measures to combat. From a socio-ecological network perspective, underlying these measures is a node lockdown strategy that locks down nodes on socio-ecological networks across all spatial scales-from the country down to cities, towns, villages,

\footnotetext{
2 The 2018 Wuhan population cited here is the latest available from the official website of the Wuhan city government (http://www. wh.gov.cn/2019_web/zjwh_5785/whgk/201910/t20191022_29087 0.html, accessed March 28, 2020). The 2020 Chinese population cited here is from Worldometer elaboration of the latest United Nations data (https://www.worldometers.info/world-population/china-popul ation/, accessed March 28, 2020).
}

neighborhoods, and homes. ${ }^{3}$ Methodically implemented, the strategy worked and worked well (Fig. 2). ${ }^{4}$

\section{A typical work-at-home day}

Professors Chen and Yuan, how would you describe a typical work-at-home day during your voluntary home self-isolation? $?^{5}$

A question from SEPR editor Wei-Ning Xiang

\subsection{Liding Chen: my hobbies}

I (author Liding Chen) usually get up at 6:00 am, check the news about the coronavirus pandemic before breakfast. In the morning, I do academic work-checking e-mails, reading, and editing student papers, reviewing manuscripts for journals, and discussing research projects with students and colleagues via the Internet. After lunch, I take a 1-hour tea break. In the afternoon, I practice one-hour Chinese calligraphy (Fig. 3) before dinner at 6:00 pm. After dinner, I watch TV news and read leisure books, while enjoying my favorite foot massage with the massage machine (Fig. 3). I go to bed at 11:00 pm.

\subsection{Xingzhong Yuan: my daily exercise and meditation in the roof garden}

Typically, I (author Xingzhong Yuan) get up at 7:30 am, exercise for half an hour in the garden on the roof (Fig. 4).

\footnotetext{
3 Wuhan city government announced the citywide lockdown on January 23,2020 . Other cities across the country followed subsequently. Seventy six days later, Wuhan ended the lockdown on April 8, 2020.

${ }^{4}$ Among newspaper articles on the effectiveness of this strategy in China's combat against the pandemic is a March 19, 2020 article in The Guardian. With a striking title China's coronavirus lockdown strategy: brutal but effective (Graham-Harrison and Kuo 2020), it is written by two reporters based in Shanghai, China.

5 The voluntary home self-isolation is a preventative measure people took under the lockdown strategy in China (Wang 2020).
} 


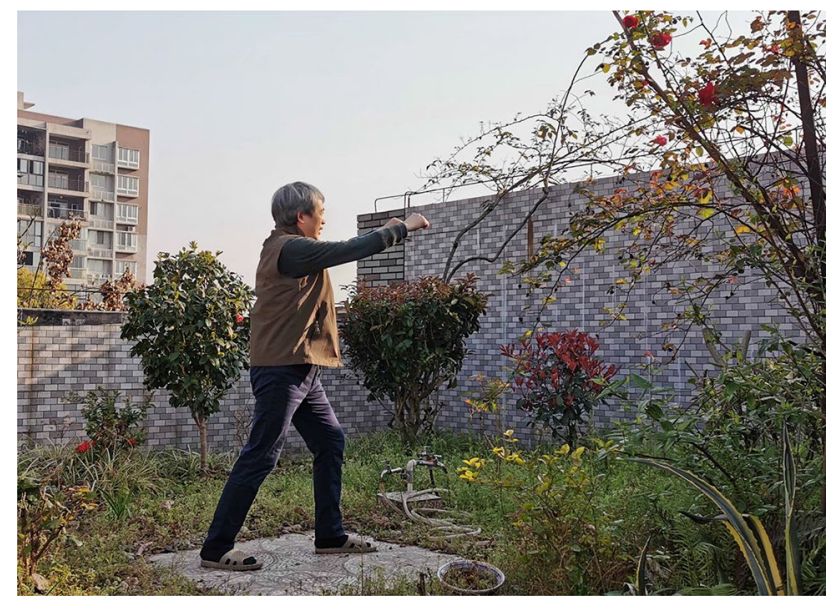

Fig. 4 Morning exercise in the roof garden (author Xingzhong Yuan does half-an-hour morning exercise daily in his roof garden in Chongqing during voluntary home self-isolation. Photograph provided by Xingzhong Yuan)

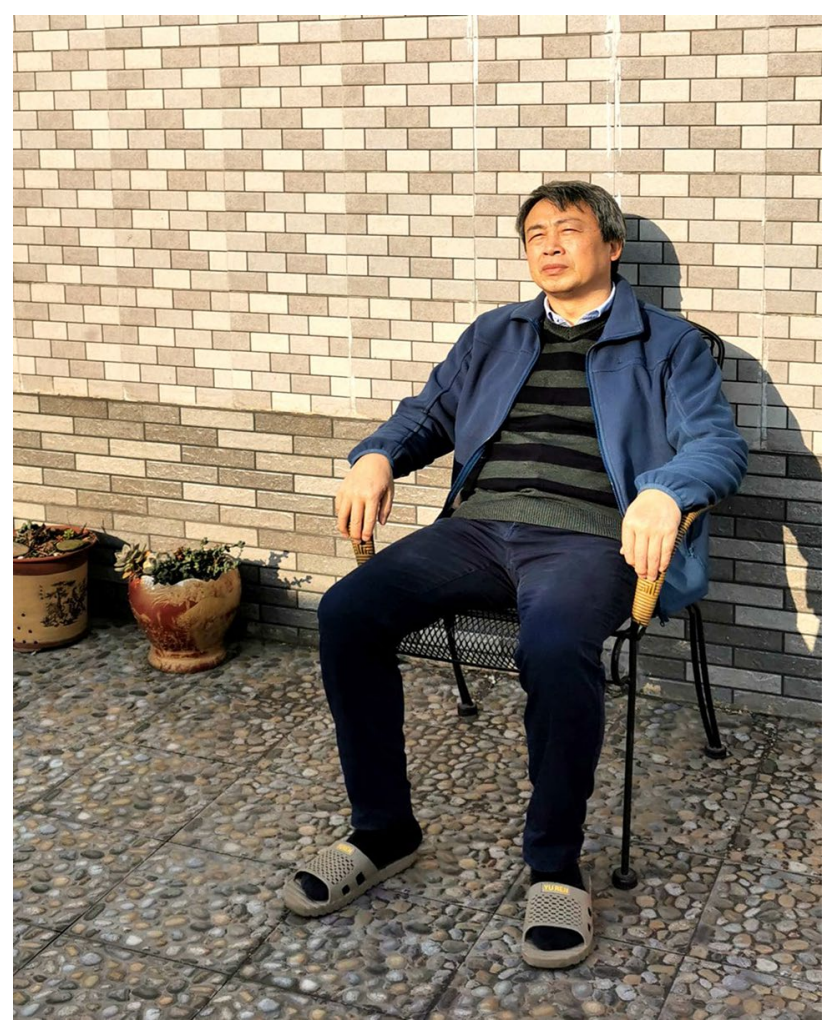

Fig. 5 Meditation in the roof garden (every day after dinner, Author Xingzhong Yuan enjoys a tranquil moment in his roof garden in Chongqing. Photograph provided by Xingzhong Yuan)
In the morning, I read books and articles and write. In the afternoon, besides reading and writing, I discuss research projects and scholarly writing via the Internet with my students and colleagues. After dinner, I meditate for an hour in the garden (Fig. 5), then read and write, and sometimes watch movies before going to bed around 11:30 pm.

\section{To pursue mindfully a fusion of human health and natural ecosystem health}

Reflecting on China's ongoing battle against the coronavirus pandemic thus far, Professors Chen and Yuan, what new insights did you find that illuminate socioecological practice and research?

A question from SEPR editor Wei-Ning Xiang

The coronavirus is malignant and detrimental to human health, but it might well be benign and even beneficial to some other beings in a natural ecosystem. This reminds us that the relation between human health and natural ecosystem health is much more complex than we understand. As such, we should be more mindful and prudent in advocating and pursuing such honorable ideals as One Health, EcoHealth, or integrative health in socio-ecological practice and research (Fig. 6; for a recent review of these ideals, see Assmuth et al. 2019). 
Fig. 6 A fusion of human health and natural ecosystem health (A noble ideal that we should strive to achieve in socio-ecological practice and research with great mindfulness)

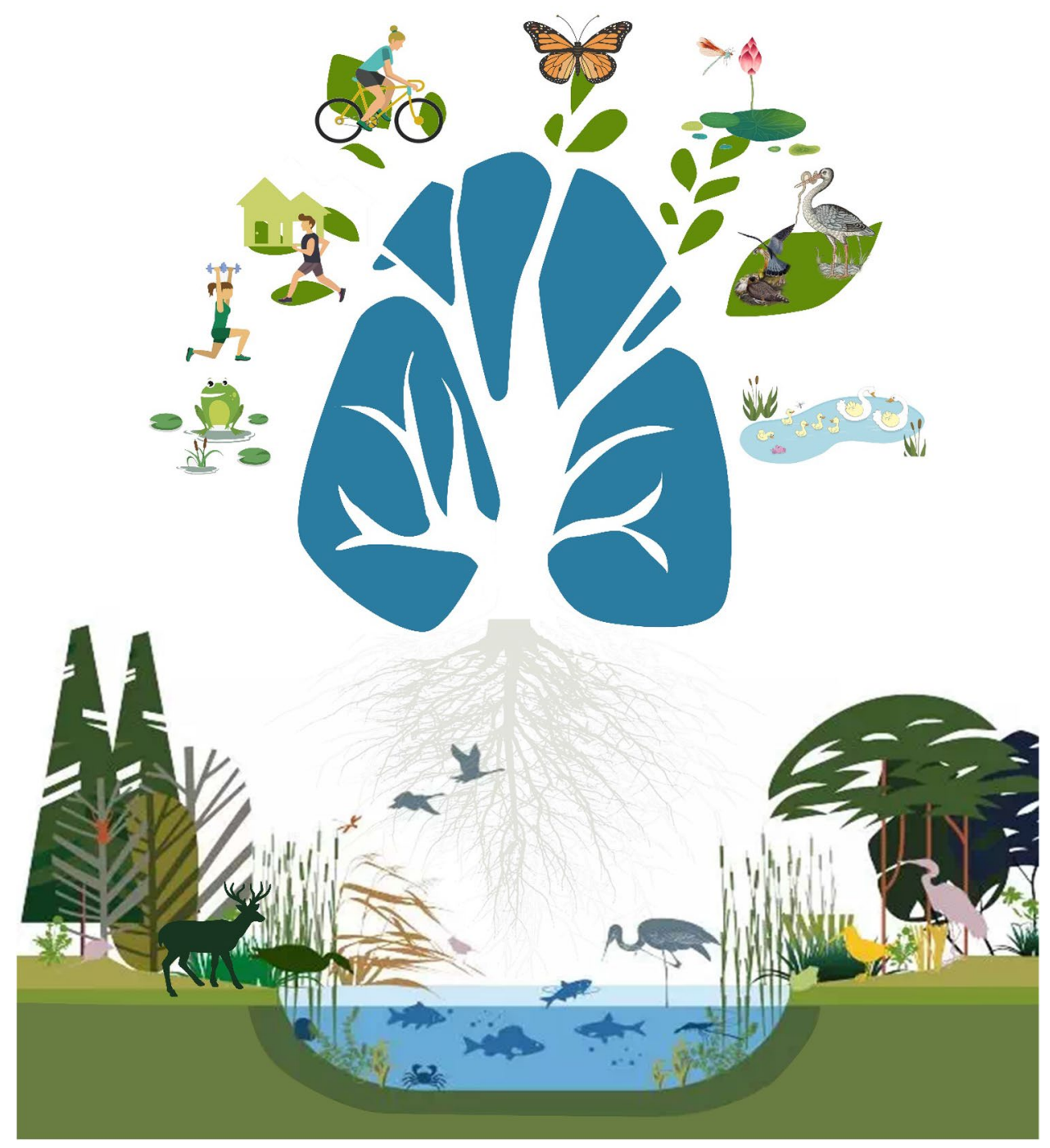

Acknowledgements We thank the following individuals who assisted the preparation of this essay (in alphabetic order): Yongcai Jing (Research Center for Eco-Environmental Sciences, Chinese Academy of Sciences, Beijing, China) who helped prepare Fig. 1, and Yangjing Liu (Ecological Research Institute of ChongqingQianzhou, Chongqing, China) who helped prepare Fig. 6.

\section{References}

Assmuth T, Chen X, Degeling C et al (2019) Integrative concepts and practices of health in transdisciplinary social ecology. Socio-Ecological Practice Research. https://doi.org/10.1007/s42532-019-00038-y

Graham-Harrison E, Kuo L (2020) China's coronavirus lockdown strategy: brutal but effective. The Guardian, https://www.theguardia n.com/world/2020/mar/19/chinas-coronavirus-lockdown-strategybrutal-but-effective. Accessed March 282020

Wang Y (2020) China's ongoing battle against the coronavirus: a scholarpractitioner's experiences and reflections. Socio-Ecological Practice Research. https://doi.org/10.1007/s42532-020-00047-2

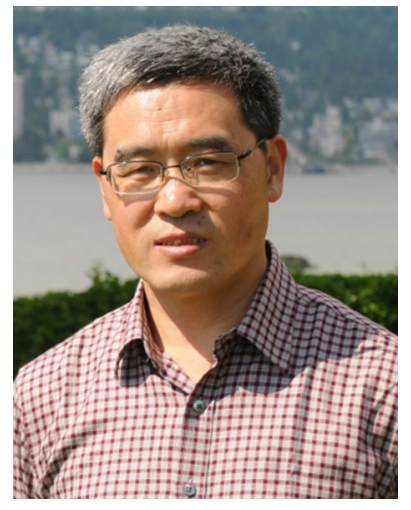

Liding Chen is a research professor in the Research Center for Eco-Environmental Sciences, the Chinese Academy of Sciences, Beijing, China. He is the vice president of both the Ecological Society of China and the International Association of Landscape Ecology. His research interests include landscape pattern and ecological processes, landscape management, and sustainable development. 


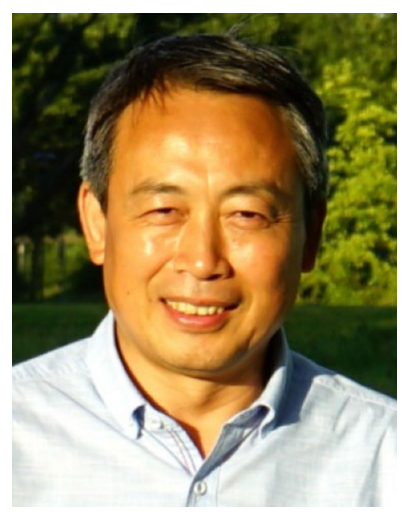

Xingzhong Yuan is a professor and doctoral advisor in the Faculty of Architecture and Urban Planning, Chongqing University, Chongqing, China. He is a member of the National Wetland Science and Technology Committee of China, and the vice president of Chongqing Ecological Society. He specializes in the practice and research of ecosystem design, landscape planning, and ecological restoration. 